\title{
Oliver Syndrome with Extensive Aplasia Cutis Congenita: A Case Report and Literature Review
}

\author{
Hamid Khay*, M.D; Mohannad Aldabbas, M.D; Mohammed Khoulali, M.D; \\ Nabil Raouzi, M.D; Noureddine Oulali, M.D; Fayçal Moufid, M.D \\ Department of Neurosurgery, Mohammed VI university Hospital, Oujda, Morocco
}

\begin{abstract}
Aplasia cutis congenita is a very rare and heterogeneous disease. It is characterized by a localized or extensive skin defect, isolated or associated with damage to the underlying structures, including the bone. The diagnosis is based on the clinical examination. Other abnormalities of various etiologies and severities may be associated with this pathology.
\end{abstract}

Adams-Oliver syndrome is a genetic polymalformative syndrome. The typical form is defined by the presence of Aplasia cutis congenita and limb anomalies.

Managing Aplasia cutis congenita, especially in severe cases, is a real challenge.

We report a case of a newborn, treated surgically, for extensive occipito-parietal Aplasia cutis congenita. The clinical presentation was suggestive of AdamsOliver syndrome. The evolution was favorable.

Describing our experience of managing a case of Aplasia cutis congenita is interesting because: the proposed treatment is very controversial, the rarity and the high morbidity and mortality of Aplasia cutis congenita and Adams-Oliver syndrome. As well as clinical and genetic diversity.

Keywords:- Aplasia cutis congenita, Adams-Oliver syndrome, surgery, scalp, treatment.

\section{INTRODUCTION}

Adams-Oliver syndrome (AOS) is a rare congenital condition. The Clinical presentation is of a wide variety as well as of variable prognosis ${ }^{1-3}$. The first description of this syndrome was in $1945^{1}$. The AOS belongs to Group 2 according to the classification of Aplasia cutis congenita (ACC) according to Frieden ${ }^{4}$. Superficial aplastic lesions have good prognosis and easily manageable by simple lesion care, treatment of infection. Surgical treatment is indicated for large skin defects accompanied by a significant risk of infection and hemorrhage. In order to avoid these risks, early surgery is indicated, the purpose of which is to recreate the skin barrier to protect adjacent structures ${ }^{5,6}$. ACC is a clinical sign for different diseases, in our case ACC was associated with AOS

\section{OBSERVATION}

A new born female, from a not followed pregnancy, delivery by vaginal route without incident, and a good adaptation to extra uterine life, the birth weight was $3100 \mathrm{~g}$. the mother is 20 years old and the father is 25 years old. At birth, the newborn was in good general condition and the neurological clinical examination was normal, while the examination of the teguments found a rounded and regular occipitoparietal skin defect, measuring $9 \mathrm{~cm} \times 13 \mathrm{~cm}$ with a crusted ulcerated center and a Cutis marmorata telangiectasia congenita (CMTC). In palpation we found a bone defect of the cranial vault opposite the cutaneous defect. The locomotor system examination found bradydactyly type $\mathrm{C}$ in the left hand (figure 1).

Seraching for other malformations showed a slight dilation of the ventricles without signs of active hydrocephaly, occipito-parietal bone defect and an atrophy of the left hemisphere with left occipitoparietal ischemia (figure 2).

The rest of the assessment, biological and radiological, was without anomaly.

The case management consisted of 5 steps:

$>$ Step 1: on admission the lesion of the scalp was covered with a sterile fatty occlusive dressing to avoid infection and hemorrhagic maceration.

$>$ Step 2: the patient was operated on at two days of life, in two stages:

- Neurosurgical time: scruples, we did the detachment and regularization of the borders of the aplasia and excision of the crusts of the ulcer. The procedure passed without incident (figure 3).

- Time of plastic surgery: a reconstruction of the cutaway was made by detaching the scalp around the aplasia and covering it with a left occipitoparietal lumbar by transposition fixed to the rest of the scalp surrounding the aplasia (figure 4).

> Step 3: betadine dressing for 3 days to avoid infection, and thereafter changes to twice-daily dressings by putting on a vaselined dressing.

> Step 4: after 2 months complete healing has been obtained with complete epidermidation of the scalp. A protective helmet has been especially made to cover the head (figure 5). 
Step 5: a follow-up every 2 months is planned for evaluation of the treatment and to search any possible complications.

The girl was referred to pediatric surgery and genetic counseling for further investigations.

\section{DISCUSSION}

AO syndrome is a rare hereditary condition with an estimated incidence of $1 / 22500$ births ${ }^{1,7,8}$. From a genetic point of view, there are six subtypes of AO syndrome, classified according to the mutation concerned (Table 1). AOS can occur in sporadic or familial form with its two presentations AD (Autosomic dominant) and AR (Autosomic recessive) ${ }^{9,10}$. Our case has no history of a similar case in the family is probably a sporadic case.

The clinical presentation is very variable, poorly characterized with the frequent presence of ACC and Limbs anomalies $1,8,11$. The Diagnostic Criteria are subdivided into major and minor criteria which are quite variable (Table 2). In the presence of two major criteria, the diagnosis of AOS is retained whereas the combination of a major criterion and a minor criterion, signifies a strong suspicion of OSA and genetic counseling is essential ${ }^{11}$. The prevalence of ACC in AOS is 75 to $86 \%$ 2,12. The anomalies of the distal extremities are $85 \%$ of variable severity, they include hypoplasia of the fingers and toes, nail dystrophies, bradydactyly and syndactyly. Hypoplasias can be partial or total in pseudo-amputations. These anomalies are typically asymmetrical ${ }^{1,13,14}$. Skin defect is more frequent at the scalp, often of occipital and parietal location, of a size rarely exceeding $10 \mathrm{~cm}$ in diameter. In complex forms, ACC is associated with a bony, dural defect and Cutis marmorata telangiectasia congenita (CMTC) ${ }^{2,10,11}$. In our case, the newborn had occipitoparietal ACC, localized CMTC and bone defect in the same localization. The CMTC can be localized or diffuse 2,14. On a literature review, the other cardiac, pulmonary, neurological, dermatological, ophthalmological, bone, vascular, genitourinary and gastrointestinal malformations are very diverse $2,11,14,15$. All these characteristics are combined in Table 2.

The objective of the paraclinical assessment is to find all the non-apparent anomalies and to evaluate the apparent ones. A polymalformative assessment is essential for diagnostic and prognostic evaluation and to plan an adequate, effective therapeutic management ${ }^{2,14,15}$

Vascular theory is the best-known photogenic hypothesis. It is related to vascular disturbances which occur between the 10th and the 18th week of amenorrhea and predominate in the areas of rapid growth $2,11,14,16$. Recent work has suggested that genetic abnormalities may the responsible of the vascular disturbances of varying degrees, depending on the genetic damage ${ }^{15,17}$.

Management is multidisciplinary, depending on the lesions present and may begin in intrauterine life ${ }^{18}$. ACC requires immediate treatment in the newborn to avoid complications. The admission management consists of making a wet, oily, sterile and protective dressing. There are no guidelines for therapeutic management. In fact, the treatment to be considered and its timing depends on the size, appearance of the lesion, the underlying lesions of the ACC, localization and the general condition of the newborn 8,19 .

Based on the form, we can distinguish two ACC forms of the scalp ${ }^{6}$ :

A membranous shape with oval or round contours which generally corresponds to a lesion with a median location with an underlying musculo-fascial and bone defect.

$>$ A non-membranous form with irregular and stellar contours, generally without defect of underlying tissues.

In our case the patient had a membranous form, of the midline, with underlying musculo-fascial and bone defect with appearance of CMTC.

The therapeutic management is very controversial according to the data in the literature. There are two options: conservative or surgical treatment. The indication for either conservative or surgical treatment is multifactorial, depending on the data on the size and severity of the disease, but also Surgery can be performed as a first line in emergencies in the presence of lesions that are deep and generally larger than $3 \mathrm{~cm}^{2}$ in sclerosulcerative appearance. Surgery is postponed sometimes if ther is initial anesthetic contraindication. Therapeutic abstention is retained before ACCs without skin involvement with less risk of complications and which does not require special care ${ }^{6,19,20}$

Conservative treatment could be achieved by using multiple products, such as different types of dressings, petroleum jelly, local or general antibiotic therapy, betadine and antiseptics. The aim is to disinfect the lesion and allow directed healing in the best conditions to avoid complications ${ }^{5,6,19,20}$.

In our case, the conservative treatment was carried out upon admission awaiting surgery. We indicated the surgery straight away, because the size of the ACC is greater than $10 \mathrm{~cm}$, with underlying ulcerative and osseous skin involvement. Excision and trimming of the ulcerated area with dissection and regularization of ACC embankments was performed followed by reconstruction by transposition flap and detachment of Merkel space. 
The principle of surgical treatment includes the excision of necrotic and infected tissue with reconstruction of the dural and cutaneous plan ${ }^{19}$. Preoperatively, careful planning of the surgical procedure is necessary and must include the neurosurgeon, the reconstructive surgeon, the pediatrician and the anesthesiologist ${ }^{8,19}$ The reconstruction options for the skin defect include the creation of skin flaps from healthy areas of the scalp in rotation or transposition and skin expansion. Bone defect in association with ACC disappears spontaneously and does not require bone reconstruction, except in rare cases where bone reconstruction is performed several years later ${ }^{20-22}$.

The reconstruction options for the skin defect include the creation of skin flaps from healthy areas of the scalp in rotation or transposition and skin expansion. Bone defect in association with ACC disappears spontaneously and does not require bone reconstruction, except in rare cases where bone reconstruction is performed several years later $19,20,23,24$.

After surgery care, patients must be placed under strict clinical-biological-radiological surveillance to watch out and treat complications at an early stage. Wound care is primordial to avoid dryness, infection and bleeding. In our case, we used povidone iodine dressings daily for the first three days, followed by a petrolatum gauze dressing every two days until complete healing. Parenteral antibiotic was given for the first three weeks of life. Several authors also recommend antibiotic therapy either prophylactic or curative $19,20,23$.

CT scan and MRI allow to precise exploration of all underlying structures and allow better planning of treatment, either conservative or surgical. In our case the defect was cutaneous, with medial ulceration but without bleeding with an extensive bone defect which explains the high risk of hemorrhage and infection of our patient. Complications occur in the first months of birth, but newborns may have sequelae associated with ACC or other conditions associated with ACC. ACC mortality varies between 20 and $55 \%{ }^{25}$.

The management of ACC requires long-term followup and the proposal of additional treatments as needed to minimize the impact of the disease ${ }^{19,20}$.

\section{CONCLUSION}

$\mathrm{ACC}$ is a rare condition that can be associated with other malformations. In our case, the patient has clinically confirmed OAS. Regardless of therapeutic management, surgical, conservative treatment or a combination of the two, treatment, a planning with regular follow-up is essential for successful management. Surgical treatment for ACC is generally offered in extensive and severe cases. Currently, advances in genetics have made it possible to diagnose family cases. Understanding this rare disease will help families with OSA, better pregnancy planning, care and follow-up.

\section{REFERENCES}

[1]. Adams FH, Oliver CP. HEREDITARY DEFORMITIES IN MANDue to Arrested Development. $J$ Hered. 1945;36(1):3-7. doi:10.1093/oxfordjournals.jhered.a105415

[2]. Kojmane W, Hmami F, Atmani S. [Adams-Oliver syndrome and cutis marmorata telangiectatica congenita]. Ann Dermatol Venereol. 2019;146(3):223225. doi:10.1016/j.annder.2018.11.009

[3]. Hassed S, Li S, Mulvihill J, Aston C, Palmer S. Adams-Oliver syndrome review of the literature: Refining the diagnostic phenotype: Adams-Oliver Syndrome: Refining the Phenotype. Am J Med Genet A. 2017;173(3):790-800. doi:10.1002/ajmg.a.37889

[4]. Frieden IJ. Aplasia cutis congenita: a clinical review and proposal for classification. J Am Acad Dermatol. 1986;14(4):646-660.

doi:10.1016/s01909622(86)70082-0

[5]. Torkamand F, Ayati A, Habibi Z, Nejat F. Extensive aplasia cutis congenita associated with cephalocranial disproportion and brain extrusion. Childs Nerv Syst ChNS Off $J$ Int Soc Pediatr Neurosurg. 2019;35(9):1629-1632. doi:10.1007/s00381-01904188-y

[6]. Schierz IAM, Giuffrè M, Del Vecchio A, Antona V, Corsello G, Piro E. Recognizable neonatal clinical features of aplasia cutis congenita. Ital J Pediatr. 2020;46. doi:10.1186/s13052-020-0789-5

[7]. Demmel U. Clinical aspects of congenital skin defects. I. Congenital skin defects on the head of the newborn. Eur $J$ Pediatr. 1975;121(1):21-50. doi:10.1007/BF00464392

[8]. Martínez-Lage JF, Almagro M, López Hernández F, Poza M. Aplasia cutis congenita of the scalp. Childs Nerv Syst. 2002;18(11):634-637. doi:10.1007/s00381002-0654-4

[9]. Meester JAN, Sukalo M, Schröder KC, et al. Elucidating the genetic architecture of Adams-Oliver syndrome in a large European cohort. Hum Mutat. 2018;39(9):1246-1261. doi:10.1002/humu.23567

[10]. McGoey RR, Lacassie Y. Adams-Oliver syndrome in siblings with central nervous system findings, epilepsy, and developmental delay: Refining the features of a severe autosomal recessive variant. Am J Med Genet A. 2008;146A(4):488-491. doi:10.1002/ajmg.a.32163

[11]. Snape KMG, Ruddy D, Zenker M, et al. The spectra of clinical phenotypes in aplasia cutis congenita and terminal transverse limb defects. Am J Med Genet A. 2009;149A(8):1860-1881. doi:10.1002/ajmg.a.32708

[12]. Messerer M, Diabira S, Belliard H, Hamlat A. Syndrome d'Adams-Oliver: à propos d'un cas d'expression minime. Arch Pédiatrie. 2010;17(10):1460-1464. doi:10.1016/j.arcped.2010.07.009

[13]. Browning JC. Aplasia cutis congenita: approach to evaluation and management: Aplasia cutis. Dermatol Ther. 2013;26(6):439-444. doi:10.1111/dth.12106 
[14]. Temtamy SA, Aglan MS, Ashour AM, Zaki MS. Adams???Oliver syndrome: further evidence of an autosomal recessive variant: Clin Dysmorphol. 2007;16(3):141-149.

doi:10.1097/MCD.0b013e3280f9df22

[15]. Lehman A, Wuyts W, Patel MS. Adams-Oliver Syndrome. In: Adam MP, Ardinger HH, Pagon RA, et al., eds. GeneReviews®. University of Washington, Seattle; 1993. Accessed June 9, 2020. http://www.ncbi.nlm.nih.gov/books/NBK355754/

[16]. Lehman A, Stittrich A-B, Glusman G, et al. Diffuse angiopathy in Adams-Oliver syndrome associated with truncating DOCK6 mutations. Am J Med Genet A. 2014;164(10):2656-2662. doi:10.1002/ajmg.a.36685

[17]. Baskar S, Kulkarni ML, Kulkarni AM, Vittalrao S, Kulkarni PM. Adams-Oliver syndrome: Additions to the clinical features and possible role of BMP pathway. Am J Med Genet A. 2009;149A(8):16781684. doi:10.1002/ajmg.a.32938

[18]. Soldado F, Kozin SH. Chapter 1 - Embryology and Intrauterine Diagnosis. In: Abzug JM, Kozin SH, Neiduski R, eds. Pediatric Hand Therapy. Elsevier; 2020:1-12. doi:10.1016/B978-0-323-53091-0.00001-4

[19]. Humphrey SR, Hu X, Adamson K, Schaus A, Jensen JN, Drolet B. A practical approach to the evaluation and treatment of an infant with aplasia cutis congenita. J Perinatol. 2018;38(2):110-117. doi:10.1038/jp.2017.142
[20]. Bharti G, Groves L, David LR, Sanger C, Argenta LC. Aplasia cutis congenita: clinical management of a rare congenital anomaly. $J$ Craniofac Surg. 2011;22(1):159-165. doi:10.1097/SCS.0b013e3181f73937

[21]. Maillet-Declerck M, Vinchon M, Guerreschi P, et al. Aplasia cutis congenita: review of 29 cases and proposal of a therapeutic strategy. Eur J Pediatr Surg Off J Austrian Assoc Pediatr Surg Al Z Kinderchir. 2013;23(2):89-93. doi:10.1055/s-0032-1322539

[22]. Beekmans SJ, Wiebe MJ. Surgical treatment of aplasia cutis in the Adams-Oliver syndrome. $J$ Craniofac Surg. 2001;12(6):569-572. doi:10.1097/00001665-200111000-00014

[23]. Udayakumaran S, Mathew J, Panikar D. Dilemmas and challenges in the management of a neonate with Adams-Oliver syndrome with infected giant aplasia cutis lesion and exsanguination: a case-based update. Childs Nerv Syst. 2013;29(4):535-541. doi:10.1007/s00381-012-1999-y

[24]. Başterzi Y, Bağdatoğlu C, Sari A, Demirkan F. Aplasia cutis congenita of the scalp and calvarium: conservative wound management with novel wound dressing materials. J Craniofac Surg. 2007;18(2):427429. doi:10.1097/01.scs.0000246500.84935.4f

[25]. D R, M C, P G, Nd H, Gi T. Aplasia cutis congenita of the scalp, the skull, and the dura. Scand J Plast Reconstr Surg Hand Surg. 2003;37(3):176-180. doi:10.1080/02844310310007809

TABLES

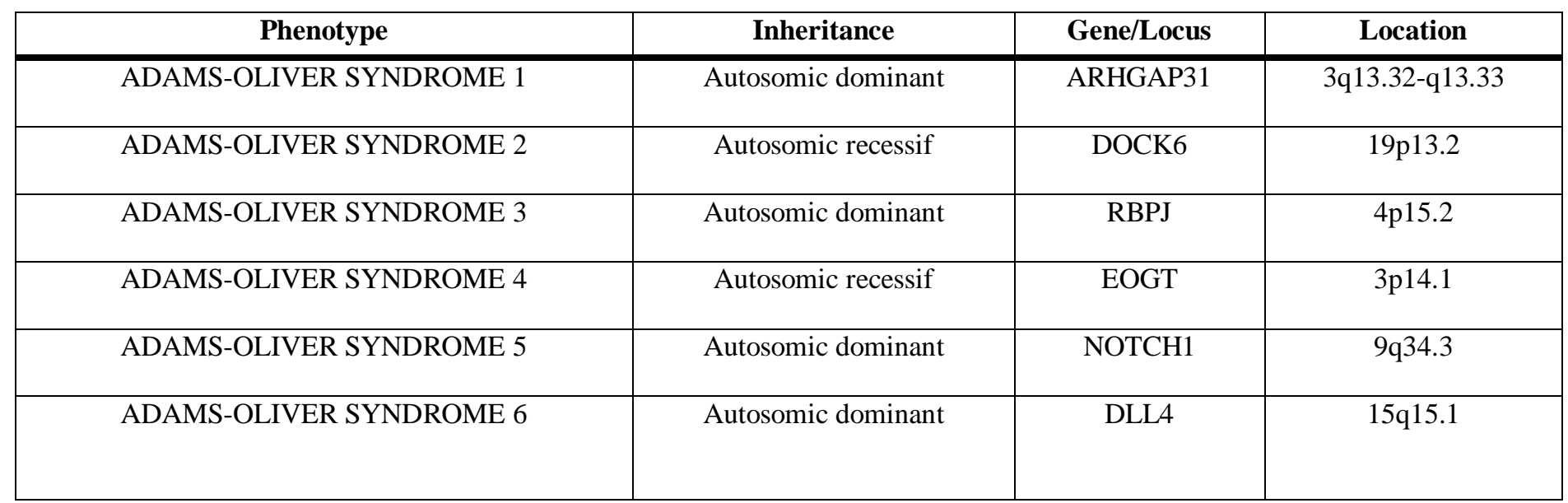

Table 1:- Répartition d'AOS en fonction du profil génétique 
ISSN No:-2456-2165

\begin{tabular}{|c|c|c|c|}
\hline Major features & Minor features & \multicolumn{2}{|c|}{ Other manifestations } \\
\hline $\begin{array}{c}\text {-Terminal transverse } \\
\text { limb defects } \\
\text { abnormalities }(85 \%)^{2,12} \\
\text {-Aplasia cutis congenita } \\
(75 \text { to } 86 \%)^{2} \text { (Kojmane } \\
\text { W 2019) } \\
\text { Family history of AOS } \\
3,15\end{array}$ & $\begin{array}{l}\text { - Cutis marmorata } \\
\text { telangiectasia } \\
\text { congenita (CMTC) } \\
\text {-Congenital cardiac } \\
\text { - Malformations } \\
\text { Vascular anomalies }\end{array}$ & $\begin{array}{c}\text { Microcephaly } \\
\text { Low hair line } \\
\text { Bitemporal depression } \\
\text { Low-set ears } \\
\text { Prominent ears } \\
\text { Esotropia } \\
\text { Microphthalmia } \\
\text { Short palpebral fissures } \\
\text { Hypertelorism } \\
\text { Small palpebral fissures } \\
\text { Strabismus (rare) } \\
\text { Microphthalmia (rare) } \\
\text { Cataract, congenital (rare) } \\
\text { congenital glaucoma } \\
\text { congenital retinal nonattachment } \\
\text { Rod dystrophy (rare) } \\
\text { Vitreoretinal abnormalities, } \\
\text { congenital (rare) } \\
\text { Optic atrophy (rare) Depressed } \\
\text { nasal bridge } \\
\text { Bulbous nasal tip } \\
\text { Cleft lip } \\
\text { Cleft palate } \\
\text { Micrognathia } \\
\text { Poland sequence } \\
\text { Accessory nipples } \\
\text { Umbilical hernia (rare) } \\
\text { Inguinal hernia (rare) } \\
\text { Hepatic fibrosis (rare) } \\
\text { Portal hypertension (rare) } \\
\text { Hepatorenal sclerosis } \\
\text { Pulmonary hypertension } \\
\text { Pulmonary arteriovenous } \\
\text { malformations } \\
\text { Chylothorax }\end{array}$ & 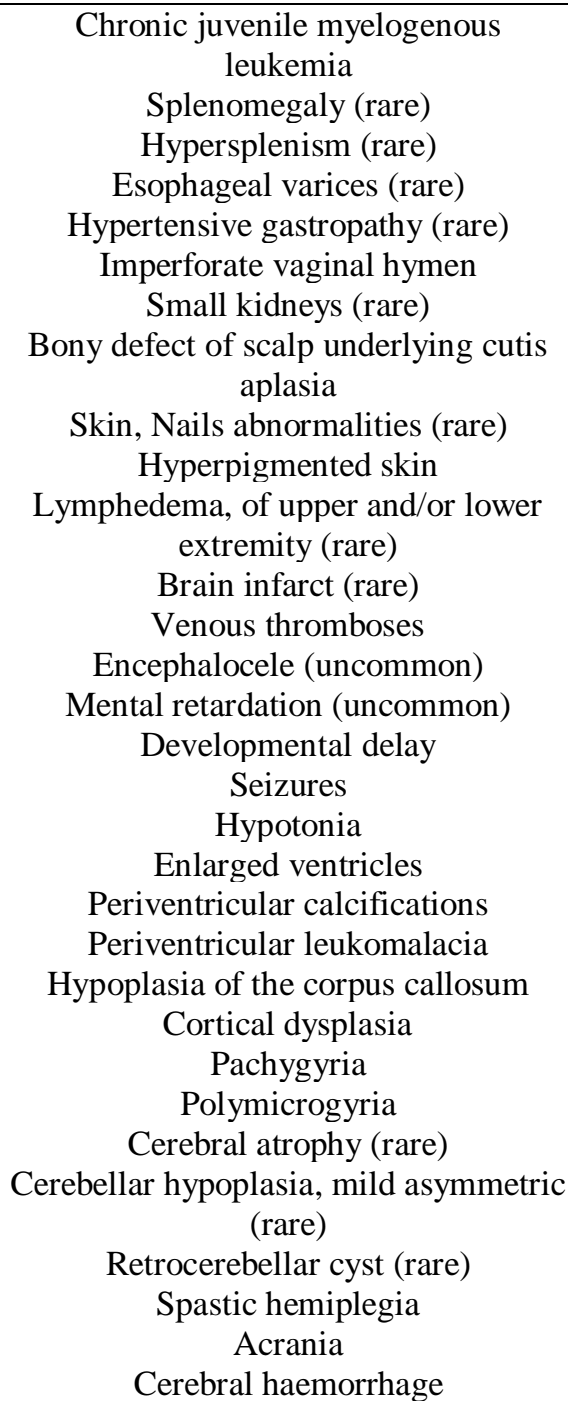 \\
\hline
\end{tabular}

Table 2 :- clinical criteria for the diagnosis of Adams-Oliver syndrome and other clinical manifestations ${ }^{2,3,11,14-16}$ :

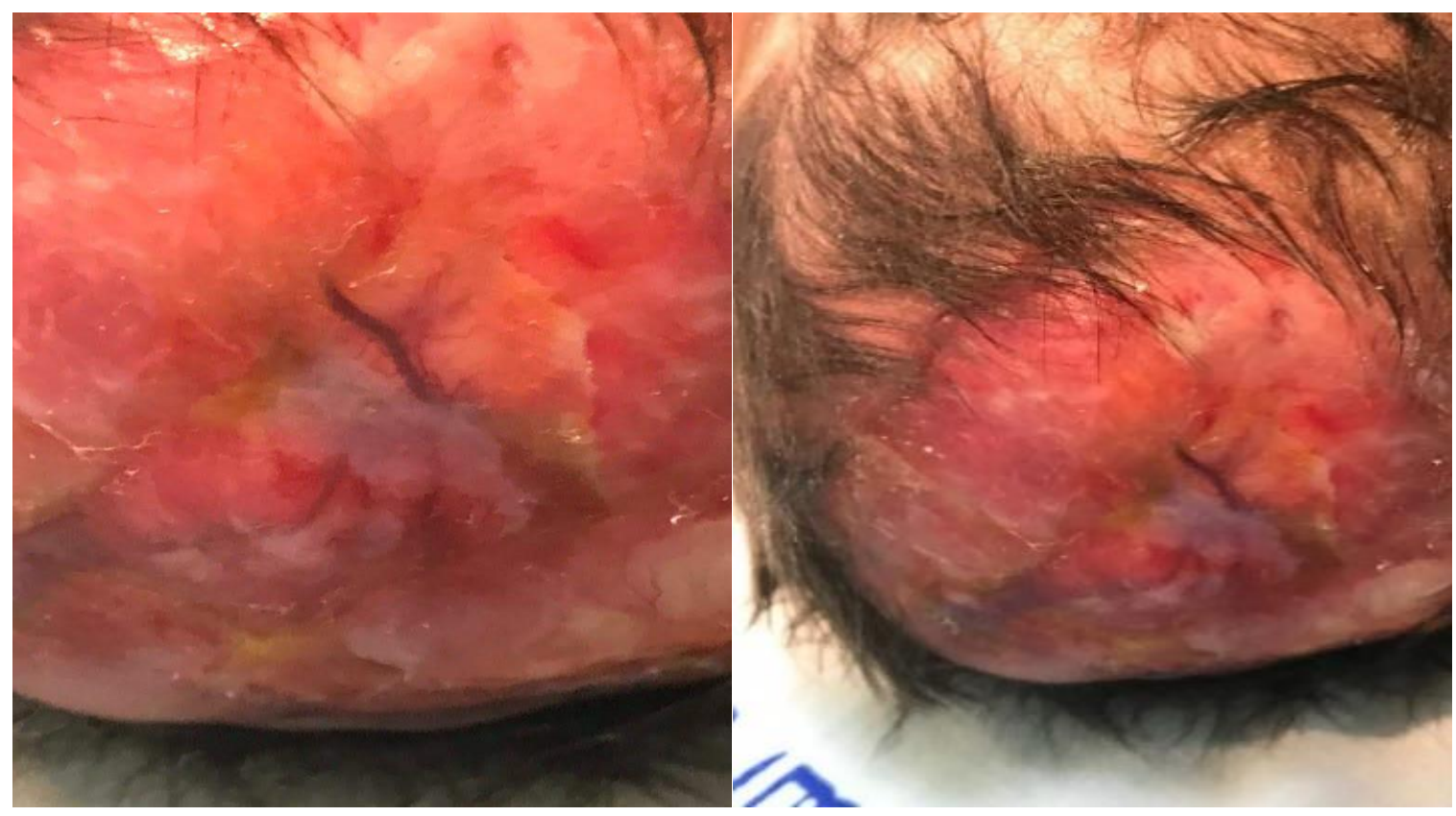



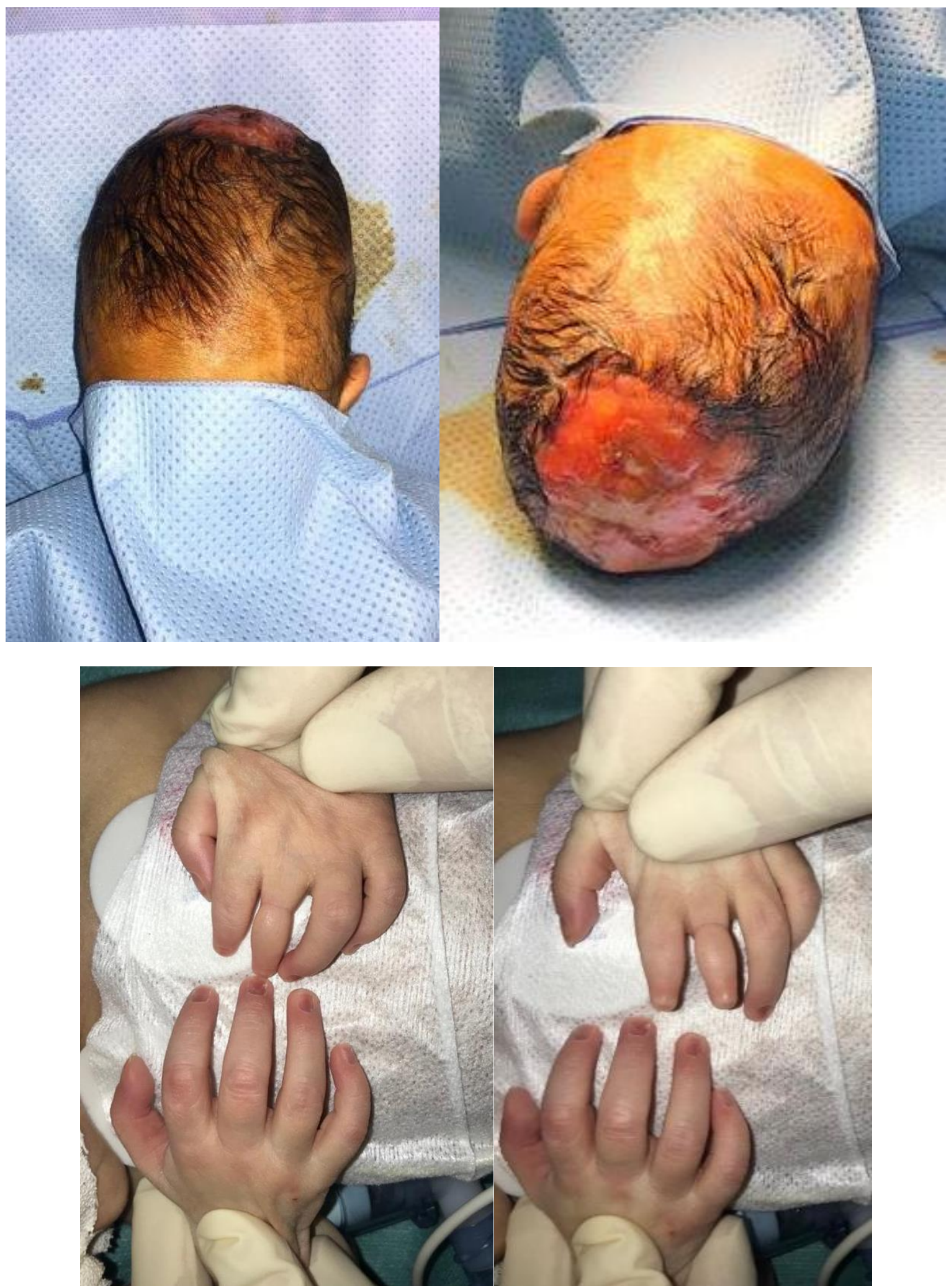

Fig 1:- preoperative image of the newborn showing the partially ulcerated occipito-parietal ACC, Cutis marmorata telangiectasia congenita and type $\mathrm{C}$ bradydactyly in the left hand. 

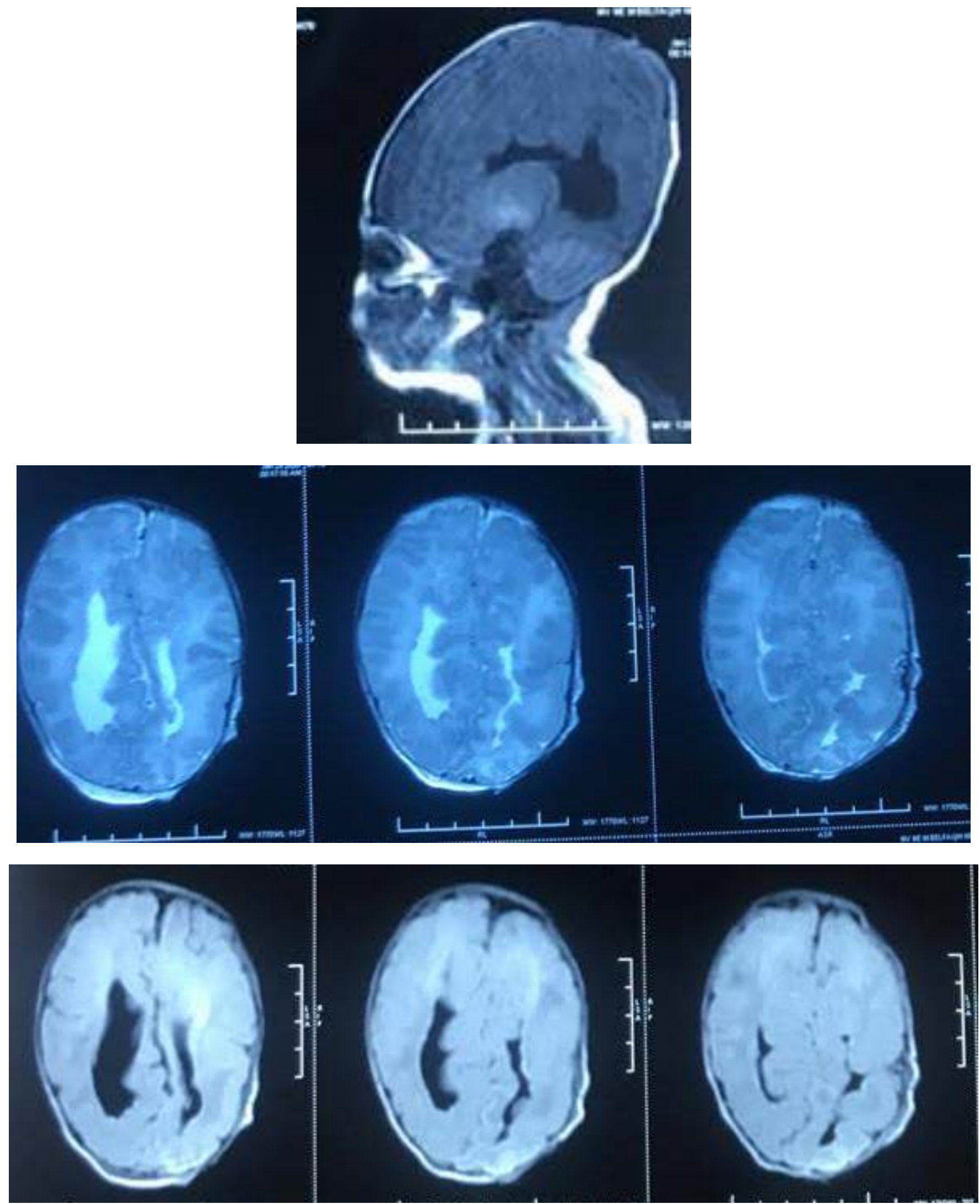

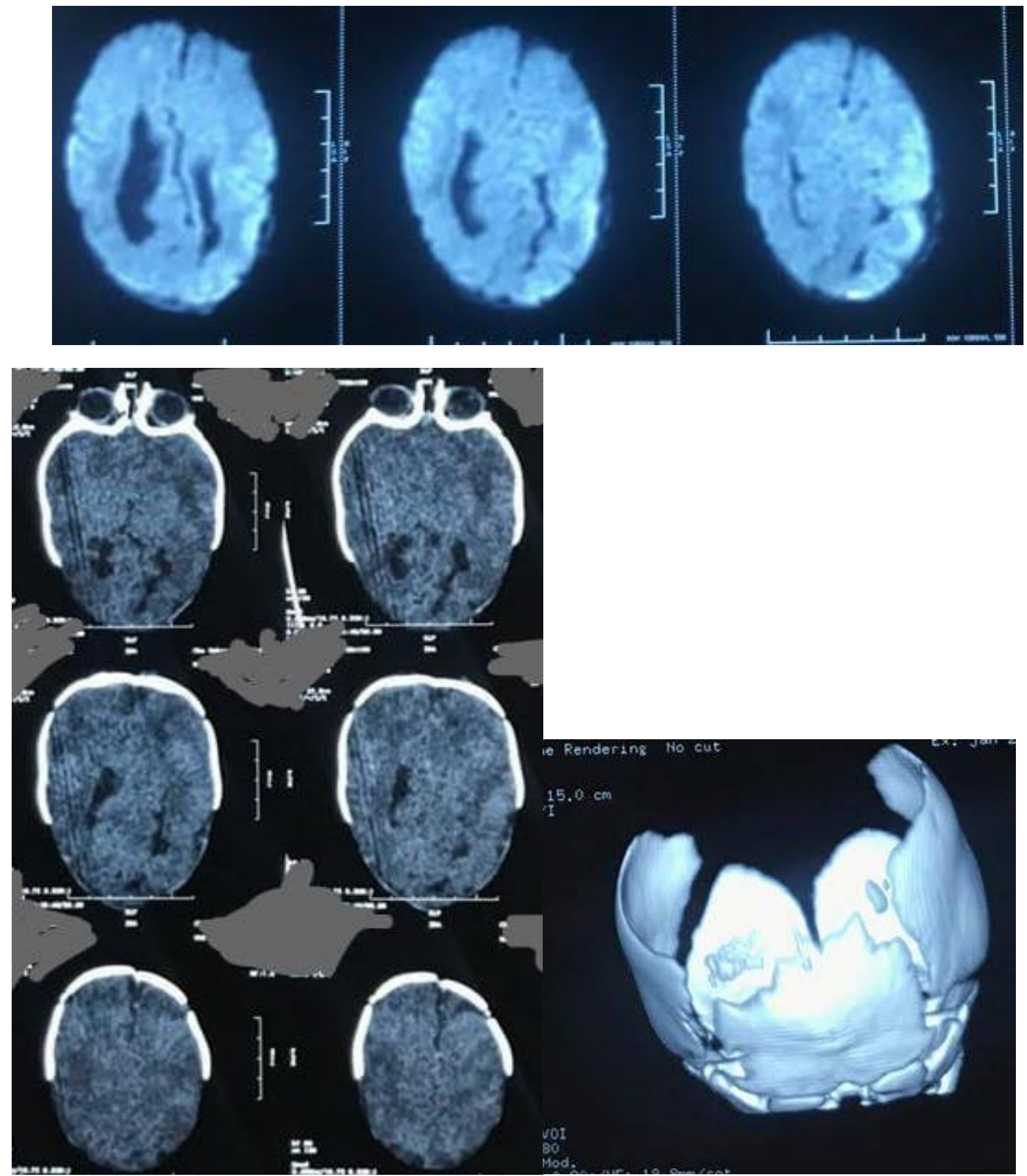

Fig 2:- CT scan and MRI of the brain showing slight dilation of the ventricles without signs of active hydrocephalus, occipitoparietal bone defect and atrophy of the left hemisphere with left occipitoparietal ischemia range. 

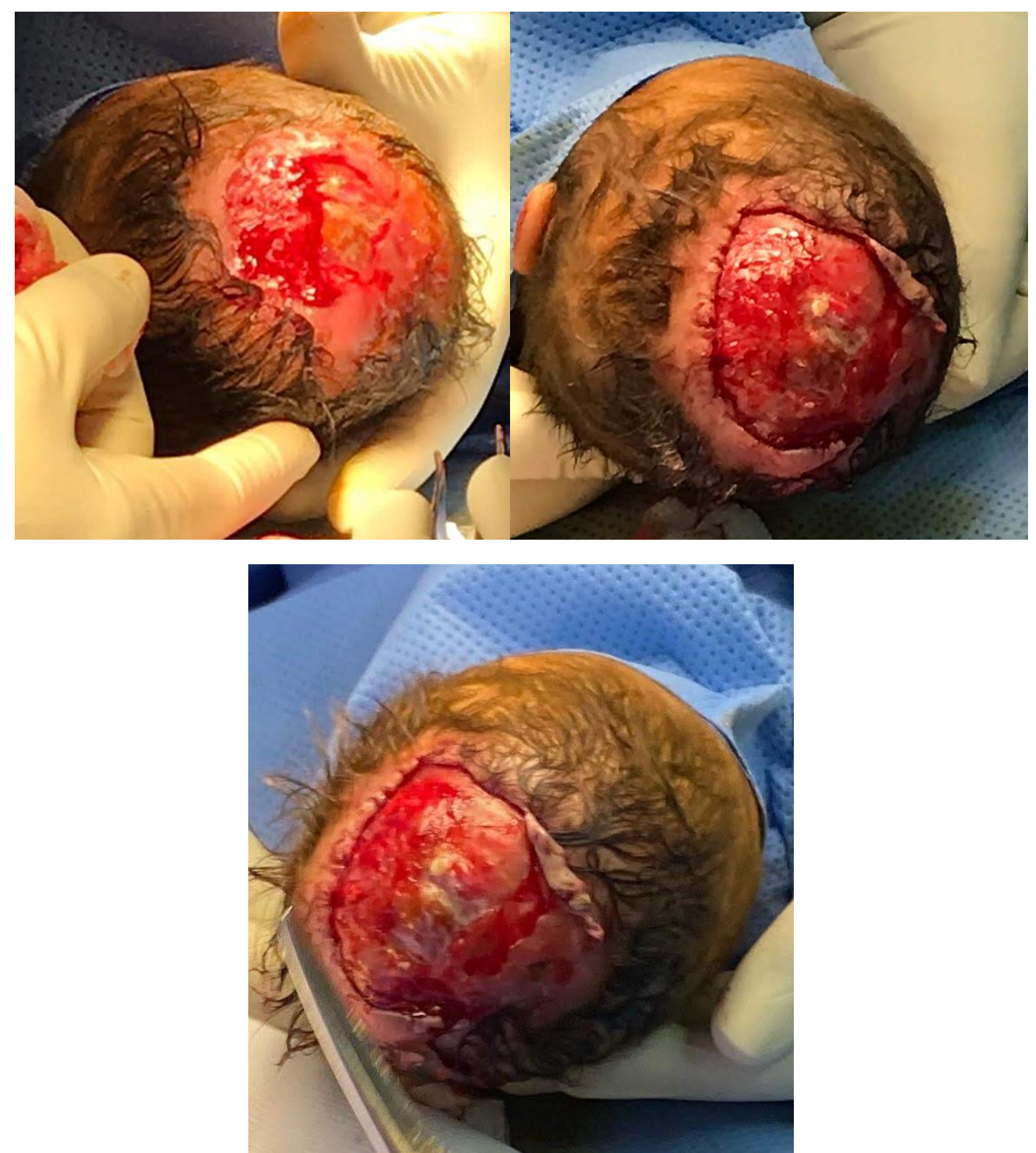

Fig 3:- Operative images showing the appearance after trimming and excision of the ACC. 


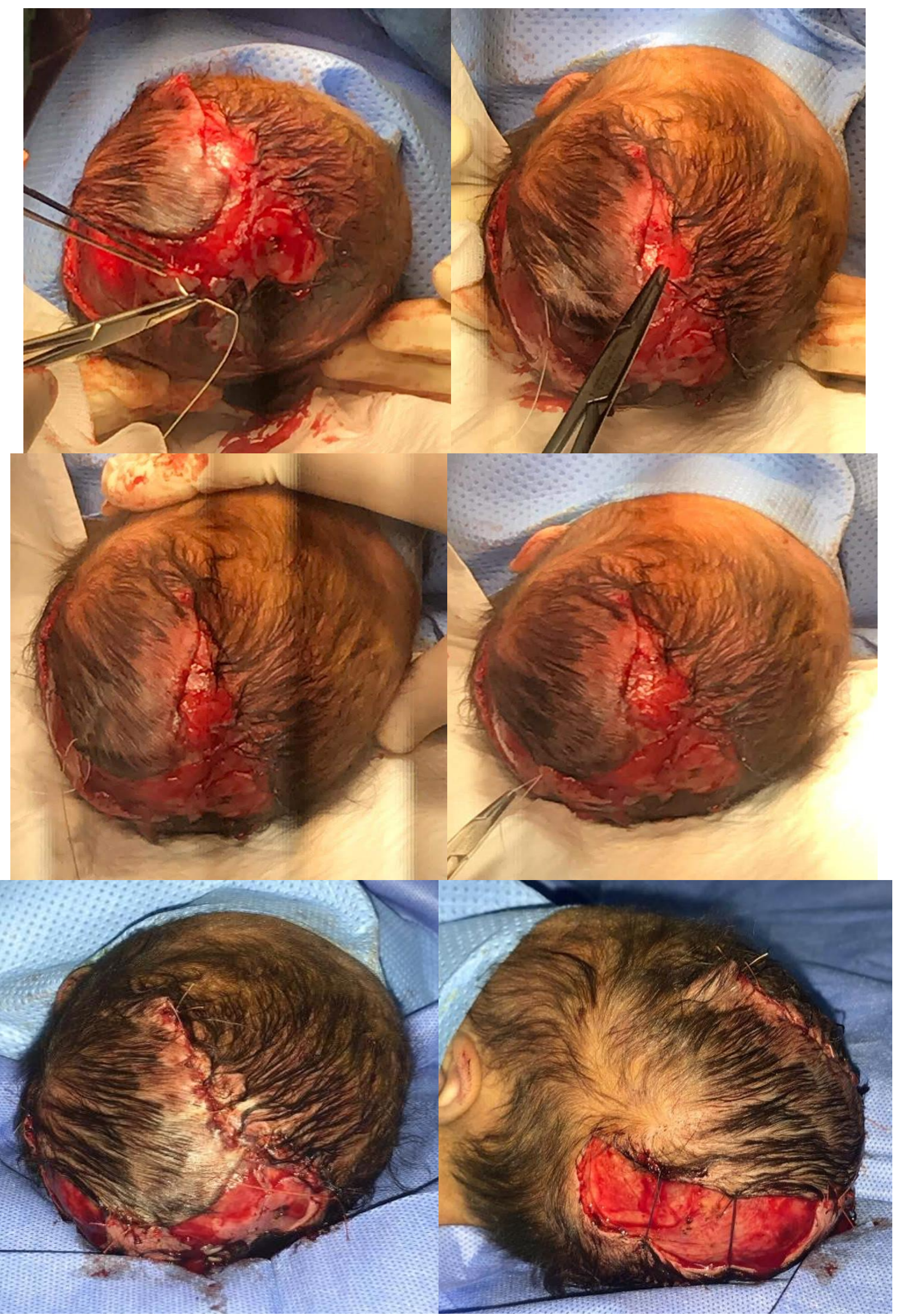

Fig 4:- Operative reconstruction images. 


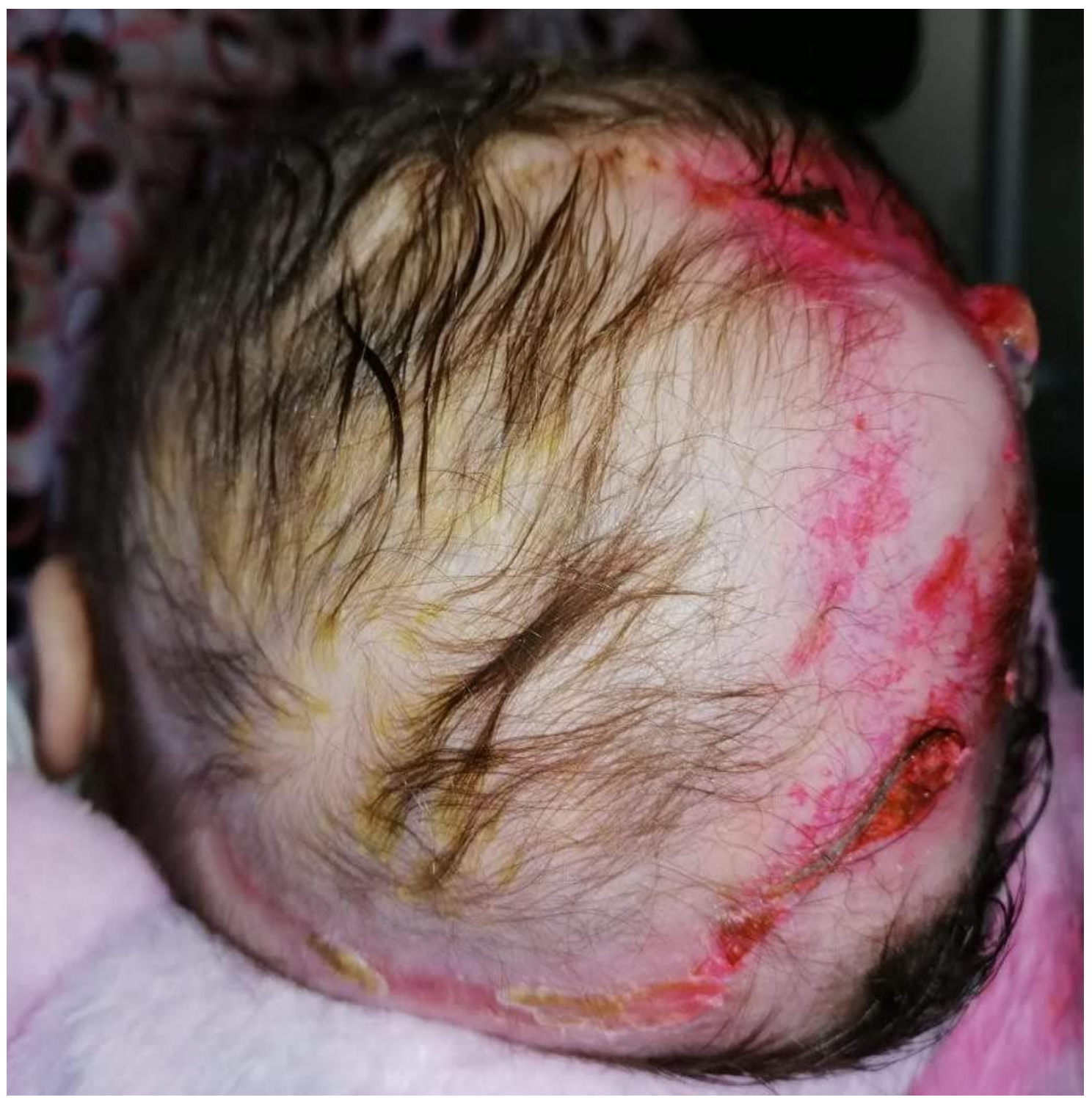

Fig 5:- image of the scar after two months postoperative. 